\title{
ENSAIO SOBRE 0 ENSAIO ONDE SOCIABILIDADE, RITUAL E PERFORMANCE SE ENCONTRAM EM UMA ESCOLA DE SAMBA
}

Ricardo José de Oliveira Barbieri (UFRJ)

Durante um período que antecede o ápice ritual do calendário carnavalesco das escolas de samba, um processo de preparação contínuo percorre seus dias. Esse período mobiliza uma rede de relações buscando alianças, espaços, representação e acionando dramas e conflitos. Buscamos aqui as formas de expressão simbólica e performática dos ensaios de escola de samba. Através da etnografia de dois ensaios em uma escola de samba de Manaus (AM) fazemos tal caminho recorrendo também a elementos tomados de ensaios nas escolas de samba cariocas. Assim, ressaltamos marcas distintivas das escolas de samba em diferentes cidades.

ESCOLASDESAMBA;ENSAIO;MANAUS;SIMBOLISMO; PERFORMANCE.

BARBIERI, Ricardo José de Oliveira. Ensaio sobre o ensaio: onde sociabilidade, ritual e performance se encontram em uma escola de samba. Textos escolhidos de cultura e arte populares, Rio de Janeiro, v.12, n.2, p. 85-102, nov. 2015. 


\section{A STUDY ON REHEARSAL \\ THE PLACE WHERE SOCIABILITY, RITUAL AND PERFORMANCE MEET INSIDE A SAMBA SCHOOL}

Ricardo José de Oliveira Barbieri (UFRJ)

During a period that precedes the apex of the ritual carnival calendar of samba school, a process of continuous preparation runs the days. This period involves a network of relationships seeking alliances, spaces, representation and triggers conflicts and dramas. This research focuses on forms of symbolic and performance expression in samba school rehearsals. Through ethnography studies of two rehearsals at a samba school in Manaus (AM) we trailed a path using elements taken from rehearsals in Rio de Janeiro samba schools. Thus, we can highlight hallmarks of samba schools in different cities.

SAMBA SCHOOLS; REHARSAL; MANAUS; SYMBOLISM; PERFORMANCE.

BARBIERI, Ricardo José de Oliveira. Ensaio sobre o ensaio: onde sociabilidade, ritual e performance se encontram em uma escola de samba. Textos escolhidos de cultura e arte populares, Rio de Janeiro, v.12, n.2, p. 85-102, nov. 2015. 
Passados os desfiles e a apuração tornou-se lugar-comum dizer que as escolas de samba não param. Um período de três a quatro meses - dependendo do dia em que a quaresma cair no ano - determina todo um processo de preparação das escolas de samba para seu ápice ritual, o desfile. Esse ciclo determina também o calendário dos envolvidos e estrutura um referencial temporal próprio, o ano carnavalesco (CAVALCANTI, 2006).

É durante esse período que toda uma rede de relações se mobiliza buscando alianças, espaços, representação e consequentemente acionando dramas e conflitos. Um ambiente conflitivo que explica as escolas de samba enquanto instituições e é marcante na edificação de suas relações com outras instituições das cidades em que estão imersas - aspectos de fundamental importância para a antropologia descobrir quais os pontos fundantes desse eixo e de que forma esses movimentos se dão. Para isso é necessário buscar a exegese nativa, aquilo que a define e que salta aos olhos em suas formas de representação simbólicas.

\section{O ENSAIO EM MÚLTIPLOS PLANOS}

Buscamos essa exegese em dois planos e locais distintos, num primeiro deslocamento etnografando outro carnaval, já numa reprodução do modelo carioca. Esse primeiro plano aqui apresentado seria o do carnaval de Manaus. Um segundo plano seria comparando essa etnografia citada com reflexões em torno de etnografias sobre o carnaval carioca, apresentando suas redes e comparando seus elementos com o ensaio nas escolas de samba de Manaus.

O caminho desta investigação começa em Manaus (AM), cidade em que as escolas de samba encontraram terreno fértil de expansão e predileção entre as festas populares. Em completo inventário sobre a história do carnaval de Manaus focando nas escolas de samba - É tempo de sambar: história do carnaval de Manaus com ênfase às escolas de samba -, o historiador Daniel Sales (2008) traça esse crescimento ano a ano até o desfile de escolas de samba da cidade chegar a ser o "terceiro maior desfile de escolas de samba do Brasil" (p. 28) perdendo apenas para os do Rio de Janeiro e de São Paulo. Nesse período que remonta ao início da década de 1990, Manaus já possuía um espaço de desfile fixo, enquanto em São Paulo os desfiles ainda aconteciam na passarela improvisada e montada na Avenida Tiradentes. Vamos até um pequeno bairro ao lado do Centro de Manaus, e um dos mais antigos, no qual o ciclo da borracha (1890-1914) deixou marcas até hoje identificáveis, o bairro de Aparecida.

Lá, a Mocidade Independente de Aparecida, fundada em 15 de março de 1980, ergue-se como um dos principais polos de movimentação cultural da cidade. A escola originada de um grupo de dissidentes da escola Em Cima da Hora, de 
outro bairro próximo, o Educandos, já foi fundada com a vocação de romper esses limites "residenciais". Por meio de desfiles luxuosos que chamavam atenção por sua "grandiosidade e seus carros alegóricos bem acabados e de muito brilho" (SALLES, 2008, p. 183), a escola conquistou 20 títulos $^{1}$ e adeptos de toda a cidade, uma história que se construiu não apenas nessas bases, mas também na rivalidade marcante entre as agremiações. Essa rivalidade em determinados momentos chegou até mesmo a desembocar no enfrentamento físico, arrefeceu, porém permanece forte até hoje na apresentação competitiva do desfile. Tomamos, portanto, inicialmente o registro etnográfico do ensaio preparatório da Mocidade Independente de Aparecida, realizado em 22 de janeiro de 2012, pouco menos de um mês antes do desfile. ${ }^{2}$

\section{O "ENSAIO DE RUA" DA MOCIDADE DE APARECIDA}

O "ensaio de rua" realizado pela Mocidade de Aparecida em Manaus mobiliza um grande número de pessoas e fecha várias ruas do bairro. Começa na Rua Bandeira Branca, frisando-a como berço sentimental do bairro, e se encerra apenas na frente da quadra da escola, na Rua Ramos Ferreira.

Em 2012, com a concentração marcada para as 17 horas, iniciou seu cortejo às 18 horas pontualmente. O trânsito se complicou não apenas pela interdição de várias ruas, mas também pela quantidade de carros estacionados nas calçadas e vias do entorno da quadra.

A escola desfilou pelas ruas do bairro com cinco alas antecedendo o casal de mestre-sala e porta-bandeira e a bateria, seguidos pelo carro de som que encerra o cortejo. $O$ trajeto sinuoso é composto de subidas e descidas, o que de certa forma marca um lugar na preparação para o desfile. Diferente da pista reta e plana, o ensaio nas ruas do bairro parece definir o caráter preparatório e, assim, se afasta do momento do desfile propriamente dito. Simultaneamente enfatiza a importância de estar no bairro e o orgulho do pertencimento ao bairro, começando pela concentração em um de seus marcos, a Praça Bandeira Branca, berço da ocupação local e residência dos moradores mais antigos e fundadores da escola. Gente de toda cidade está lá, celebrando essa ligação com o bairro de Aparecida.

A bateria é a grande atração do ensaio, com a maior parte das pessoas se concentrando a seu lado e a acompanhando durante o cortejo. Sua importância nesse momento é significativa e denotada não apenas pela permanência do público em seu entorno, pois boa parte dos diretores e até mesmo o presidente ali se concentram. As manobras de entrada e saída do chamado recuo de bateria são ensaiadas exaustivamente. Trata-se de um movimento que permite a harmoniza- 
ção do som da bateria entre os componentes através de seu posicionamento em espaço recuado exatamente na metade da pista de desfile. Em determinado ponto do trajeto tal movimento foi ensaiado. Essa entrada é motivo de atenção pela possibilidade da abertura de buracos ou pela grande probabilidade de problemas rítmicos, o chamado atravessamento de bateria. Antes da entrada na Ramos Ferreira, onde fica a quadra da escola, o trajeto apresenta ainda uma curva, sinalizando também a parte final do ensaio de rua.

Durante todo o trajeto notamos a presença de moradores que acompanham o ensaio de sacadas e janelas das casas. Interessante observar que no maior edifício do bairro, bem próximo à quadra, não havia ninguém nas sacadas. Soubemos, em ensaios anteriores, que alguns dos moradores desse edifício não estariam satisfeitos com o barulho causado pelos ensaios. Haveria, aliás, um movimento desses moradores no sentido de tentar fechar a escola. Quadro bem diferente das pequenas casas, que muitas vezes são até mesmo decoradas com as cores verde e branca, alusivas à escola. Alguns dos moradores aproveitaram essas noites de ensaio para transformar suas varandas ou garagens em ponto de venda de bebidas para os componentes e o público do ensaio. Exceto pelo tal edifício, a integração do bairro com a escola pareceu harmônica. A passagem da escola pela rua da maior igreja dessa área coincidiu com o final da missa e até uma igreja evangélica localizada na rua da quadra realizava normalmente seu culto, apesar da passagem da bateria exatamente diante de sua porta.

O ápice do ensaio aconteceu por volta de 20 horas, quando o carro de som e a bateria chegam em frente à quadra. Nesse momento, centenas de pessoas costumam aglomerar-se aguardando a chegada da bateria. Todos, componentes e público, se aglomeraram no entorno da entrada da quadra. Quando a bateria ali chegou fez um intervalo para que seus componentes descansassem e os integrantes do carro de som descessem para a continuação do ensaio no palco montado em frente à quadra.

Após o intervalo os cantores se posicionaram no palco para a retomada do ensaio. Nessa segunda parte cantaram sambas conhecidos de escolas cariocas como União da Ilha, Salgueiro, Mangueira e Mocidade. O samba de 2010 da Grande Rio foi executado mais de uma vez e entusiasmadamente pela bateria. As chamadas convenções desse samba parecem ter sido adaptadas para o samba de 2012 da escola, o que explicaria o entusiasmo e a repetição. O carnaval carioca apareceu também em outra adptação, a do samba-exaltação da Mocidade Independente de Padre Miguel "Não existe mais quente", e o verso "Padre Miguel é a capital" virou "Aparecida é a capital". Logo depois mais um intervalo aconteceu, sendo ocupado por um discurso do presidente da escola, em determinado tre- 
cho do qual aparece a rivalidade entre as escolas, servindo para exaltar as qualidades da escola:

Quem aí torce para a Vitória Régia? Aquele ali no fundo! E com certeza tá gostando do ensaio porque aqui é um lugar familiar. Todo mundo pode curtir o samba com tranquilidade e segurança. Aqui não tem bandido, não tem coisa errada. É o melhor samba da cidade (presidente Pacheco, 22/1/2012).

Terminada a execução de sambas antigos, o evento prosseguiu com o samba de esquenta da escola e a seguir o samba do ano. A corte ${ }^{3}$ permaneceu diante da bateria, posicionada de frente para o palco com o público ocupando as laterais. Uma miniala de aprendizes de tamborim colocou-se de frente para a ala de tamborins, que forma a primeira fileira da bateria.

Presentes ao ensaio, circulando entre o palco e as proximidades da bateria, o carnavalesco e parte de sua equipe de assistentes marcavam presença. Diferente da maior parte dos carnavalescos de Manaus, o da Mocidade de Aparecida não teve como destaque em sua carreira o trabalho no festival de Parintins, mas única e exclusivamente nas escolas de samba. O carnavalesco Saulo Borges chegou a ter sambas dedicados a ele e até mesmo cantar um samba da Beija-Flor com a bateria e os puxadores oficiais.

No palco a presença de ilustres era constante - parentes do governador, funcionários e secretários de governo ou da prefeitura e patrocinadores da escola. O tempo todo e com grande destaque, abraçada ao presidente da escola, estava uma importante radialista. Ela chegou a pegar o microfone para agradecer a recepção e declarar seu amor pela escola.

Enquanto cantavam o samba do ano todos esses citados e presentes no palco improvisado na frente da varanda-bar da escola estavam abraçados e sorrindo, quando abruptamente um dos integrantes da harmonia discutiu com alguém logo atrás do palco e uma briga interrompeu o ensaio. A confusão generalizada envolveu o diretor de harmonia, que foi seguro por diversos componentes da escola, e um homem que não consegui identificar e foi descrito por um dos presentes como "alguém de fora da escola". O diretor de harmonia em questão era também apresentador e dono do bar da escola. Com o ensaio encerrado, o mestre de bateria passou orientações a seus componentes sobre um ensaio só com a bateria a ser realizado numa terça-feira à noite na quadra da escola, com entrada restrita aos componentes da bateria. 


\section{A FUNÇÃO POLÍTICO-INTEGRATIVA DO “ENSAIO" DE ESCOLA DE SAMBA}

Tomando as noções de Victor Turner $(1974,1982)$ sobre ritual, podemos analisar as categorias nativas acerca do ensaio de escola de samba. A importância das escolas de samba nos estudos de ritual já foi bastante explorada. Tomada ainda dentro do contexto urbano a importância de tal análise se amplia. $\mathrm{O}$ caso aqui focalizado, um ensaio de escola de samba em Manaus, se enquadra nos exemplos citados na obra de Turner, cujas noções vamos recuperar.

A obra de Victor Turner sempre destacou os temas do ritual e simbolismo. Tais dimensões da análise social demonstraram sua importância vital em diversos aspectos. Em Schism and continuity in African Society: a study of Ndembu village life (1996), a principal marca está na elaboração da teoria do "drama social" aplicada aos conflitos entre os Ndembu. A importância do método salta aos olhos quando notamos que por seu intermédio é possível acessar as mais importantes dimensões do funcionamento da sociedade ndembu, como a matrilinearidade, nas relações de parentesco. Turner demonstra como a coesão é mantida em múltiplas afiliações sociais e até mesmo através de processos de conflito.

Nos dramas apresentados na obra comprovamos como pessoas que rivalizam em uma relação social são aliadas em outras. Além disso, foi possível acompanhar como a coesão social pode ser mantida ou quebrada após um conflito entre algumas pessoas. Finalmente, após um extenso capítulo antecedente tratando das vizinhanças e distribuição demográfica ndembu, Turner demonstra como as aldeias são um grupo de pessoas unidas por princípios de filiação social com aspectos dominantes em certas situações.

Seria necessário tomar o ensaio de escolas pelo modelo processual em que Turner (1996) desenvolve seu drama social: em quatro fases, a saber, quebra, crise, ação reparadora e reintegração ou reconhecimento do cisma. Podemos nos arriscar, entretanto, a observar o desenrolar de alguns pequenos conflitos no caso analisado que demonstram importantes aspectos da sociabilidade nas escolas de samba.

A tomada de posição em relação ao desfile já pode ser observada na posição dos diretores no desenrolar do desfile. Ficar perto ou cuidar do "recuo da bateria" denota prestígio que pode servir como moeda de troca em outras ocasiões ou situações futuras dentro do universo das escolas de samba. Cuidar desse aspecto fundamental, da posição em que estão o presidente, o casal de mestresala e porta-bandeira, a bateria, "o coração da escola", é fundamental no aspecto relacional nesse universo. 


\section{OS ENSAIOS NO PROCESSO RITUAL DAS ESCOLAS DE SAMBA}

Seria conveniente, portanto, um estudo que explicite a importância da posição do diretor de harmonia para a escola de samba. Os critérios que colocam em jogo esse cargo denotam uma carga de valores que vai além, mas também compreendem a posição no desfile ou o domínio de técnicas em determinada área de conhecimento. $\mathrm{O}$ acesso ao secreto e a colocação das pessoas em posições-chave nas escolas passam por isso. É importante guardar segredos nas escolas, pois eles são a chave para sensibilizar os jurados na competição com outras escolas de samba. Esses segredos vão além dos guardados nos barracões e já demonstrados em diversos trabalhos sobre o tema. ${ }^{4} \mathrm{O}$ ensaio "secreto" de bateria marcado pela escola para o início da semana vira moeda de troca, e esse conhecimento entra em jogo para a preparação ritual, na disputa de posições de confiança junto ao presidente, carnavalesco, diretor de bateria e harmonia. Em determinado momento, um componente ligado ao diretor de bateria me ofereceu "entrada exclusiva" para assistir ao tal ensaio secreto. Tal proposta denota o prestígio do componente citado junto à cúpula da escola.

A rivalidade com outras escolas torna-se clara não apenas na competição para surpreender com apresentações superiores e mais emocionantes do que as das rivais. Isso passa por critérios técnicos que envolvem os quesitos em julgamento, denotados pela importância das manobras e apresentação compacta das escolas mesmo nas ruas do bairro. Por outro lado, as escolas competem pela presença de público nos ensaios. Ter o melhor ensaio significa ser a escola "mais bem frequentada". Para oferecer o melhor ambiente não apenas a seus simpatizantes e visitantes, bem como aos visitantes de escolas rivais, o discurso unifica em oposição às demais.

Vemos nessa a tonalidade agonística em que as escolas se associam e rivalizam simultaneamente. O discurso do presidente da Aparecida aqui transcrito poderia soar para muitos torcedores rivais como uma provocação, por mais que parecesse a alguns dos componentes da Aparecida um discurso que ressalta a boa acolhida dos rivais.

A importância do receber e doar melhor que o rival, o aspecto relacional, se aproxima à das relações entre aldeias vizinhas e nos fazem pensar sobre a importância da teoria de Turner especialmente em situações de sociabilidade conflitiva, como no caso das escolas de samba. 


\section{A RIVALIDADE ENCENADA EM UM ENSAIO NA QUADRA DA APARECIDA}

Pude etnografar uma das formas mais interessantes de sociabilidade num ensaio de escola de samba em um encontro das escolas de samba Vitória Régia e Mocidade de Aparecida, na quadra desta última em Manaus. Destaco incialmente a rivalidade que coloca as duas escolas em campos opostos no carnaval de Manaus.

Fundada em 1975, a verde e rosa Vitória Régia localiza-se no bairro Praça 14 de Janeiro, próximo da zona central da cidade de Manaus. Carrega consigo a marca de "Berço do Samba" por ter-se originado da Escola de Samba Mixta da Praça 14, considerada a primeira escola de samba de Manaus, fundada em 1947. Além disso, a Praça 14 é reconhecidamente um bairro festeiro, destacandose especialmente as festas ligadas à população maranhense que ainda no século XIX ocupou o bairro. Assim, desde muito cedo o samba emerge com destaque no cenário do bairro, praticado nos terreiros de candomblé das "tias" e "mães" do bairro. Na década de 1970 a Vitória Régia se distingue no carnaval da cidade, conquistando títulos até o surgimento da Mocidade de Aparecida, que praticamente se revezará com ela ano a ano no posto de campeã do carnaval. Nesse período a disputa do posto de melhor escola do carnaval de Manaus se acirrará de tal forma, que muitas apurações terminariam em pancadaria.

Simbolicamente um campo de oposições se constrói no universo carnavalesco de Manaus entre essas escolas. Enquanto a Vitória Régia buscava o apelo popular em seus desfiles, a Aparecida, como já relatamos aqui, prezava o luxo de suas fantasia e alegorias. Logo a Vitória Régia tomou para si a alcunha de "escola do povão". A Aparecida foi colocada no campo oposto. Apesar de tais categorias quase sempre não serem verificadas na realidade, posto que o princípio das escolas de samba em geral é ser popular, elas funcionam no imaginário dos sambistas. Vez por outra, também marcam presença no discurso de seus componentes, como quando o presidente Pacheco enaltece a tranquilidade de seus ensaios e não a grande presença de público.

O número de títulos é outro campo em que as escolas rivalizam. Os sambistas da Vitória Régia fazem questão de colocar-se como herdeiros da Escola Mixta da Praça 14, como nos informa o conselheiro da escola, Betão, em entrevista realizada na quadra da Vitória Régia em 18/11/2013:

Tem muita escola aí, que eu não vou falar nome, que vai botar nome lá pra fazer ensaio na sua quadra. Nós não, nós temos história. Nós temos 28 campeonatos no carnaval de Manaus, 15 com a Mixta e 13 com a Vitória Régia. 


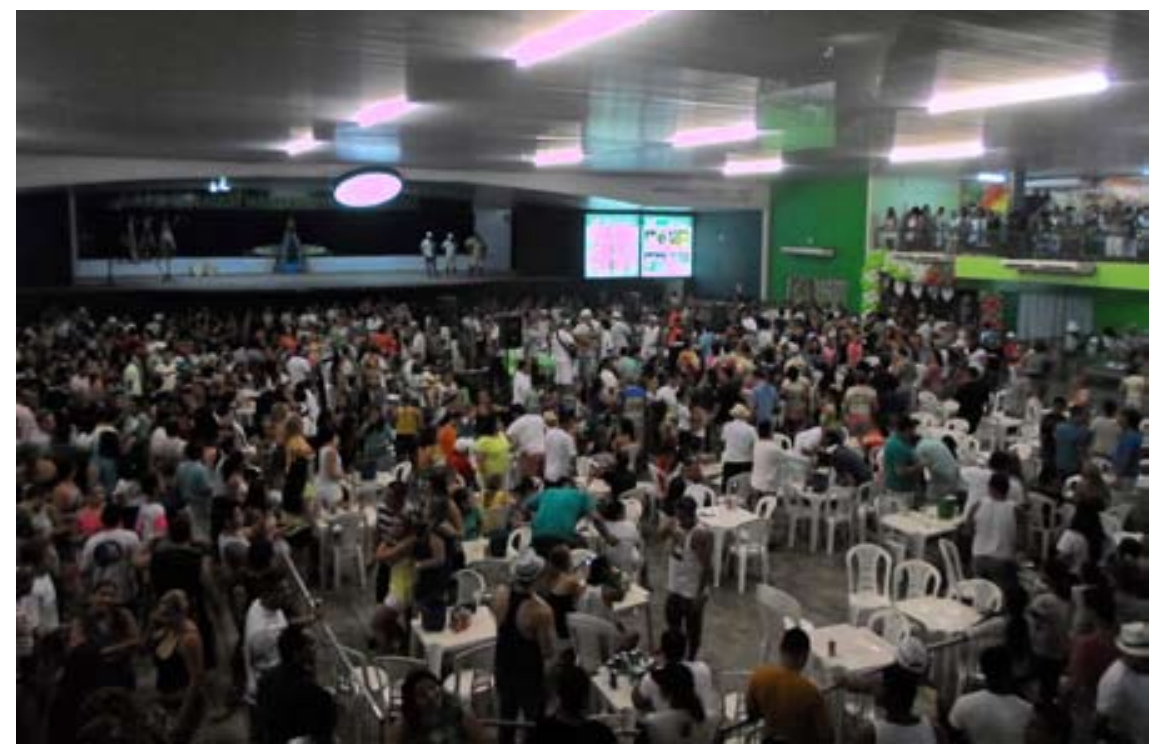

Figura 1: Interior da quadra da Mocidade de Aparecida

A Vitória Régia tem $11^{5}$ títulos - e não 13 , como declarado por Betão - reconhecidos oficialmente. A esses seus torcedores acrescentam os 15 campeonatos conquistados pela antiga escola Mixta da Praça 14, somando, portanto, 26 taças. Tudo isso para ultrapassar os 20 títulos da rival Mocidade de Aparecida.

Esse é o quadro em que as duas escolas se encontraram num show realizado na quadra da Mocidade de Aparecida num dos domingos antecedentes ao carnaval em que a Aparecida promove seu chamado ensaio comercial - categoria já descrita em escolas cariocas, como veremos a seguir, para designar os ensaios em que a entrada é cobrada. O evento denominado "Aparecida encontra" já reunira outras escolas de samba de Manaus, mas de grupos inferiores ao Especial, que a Aparecida disputava com a Vitória Régia. Foi inspirado em encontros de escolas de samba promovidos no Rio de Janeiro pela Acadêmicos do Salgueiro (Figura 1).

A noite prometia bom público, por isso cheguei cedo e me posicionei próximo ao palco da bateria, até para observar se haveria a interação entre ritmistas, casais de mestre-sala e porta-bandeira e baianas que marcam as visitas entre as escolas no Rio de Janeiro. Com a quadra já toda tomada de público, os sambas de 1993 e 2014 da Mocidade de Aparecida foram executados, dessa vez para apresentação dos casais de mestre-sala e porta-bandeira. Foram dois casais adultos e um mirim. O primeiro casal da Aparecida permaneceu no palco para a recepção subsequente do casal da Vitória Régia, numa cerimônia formal e ritualizada. 


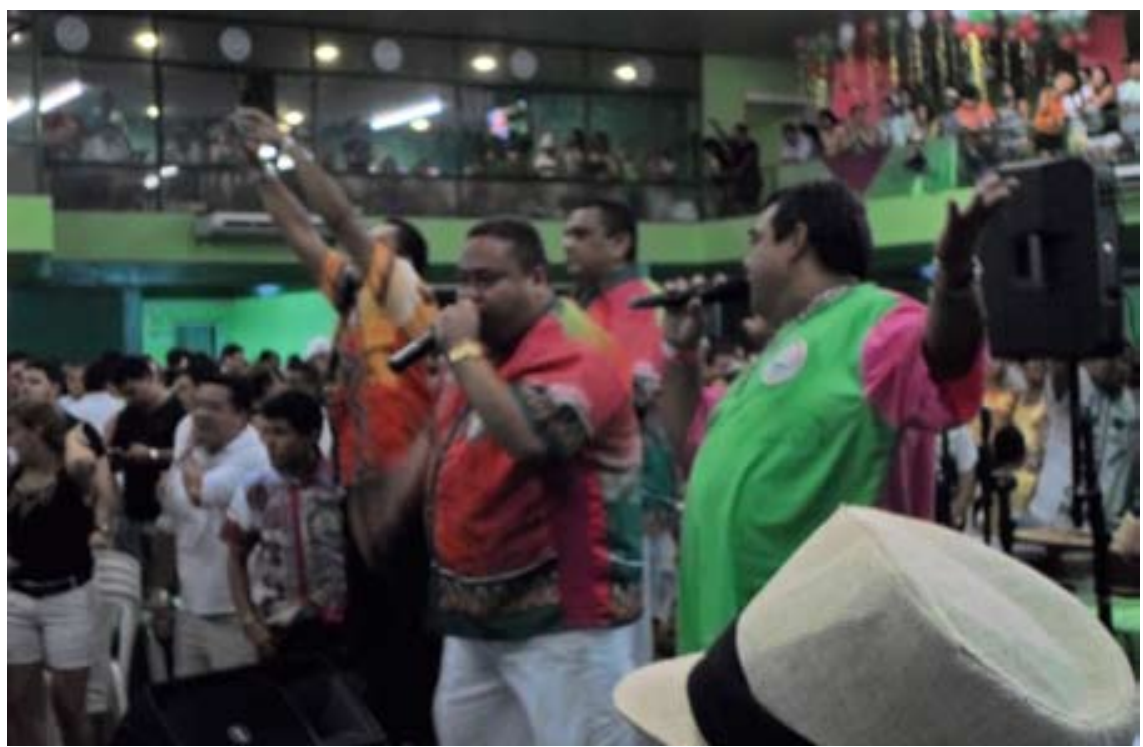

Figura 2: Prince do Boi (ao centro) cantando no palco da Aparecida

No discurso que antecedeu a apresentação da Vitória Régia, os presidentes exaltaram o momento de "união pelo carnaval". O presidente da Aparecida fez questão de reconhecer o pioneirismo da Vitória Régia no carnaval de Manaus. e o da Vitória Régia a grande estrutura da Aparecida. Ambos frisaram que o momento era difícil e que "as escolas precisavam unir-se para cobrar seus direitos". O presidente Ivan Martins saudava a Aparecida por abrir as portas para recebêlos em sua bonita quadra. A quadra da Aparecida passara por reformas recentemente. Reformas polêmicas, custeadas pelo governo do Estado do Amazonas comandado por Omar Aziz, declarado torcedor da Aparecida. Nas reformas, além da climatização, a quadra recebeu tratamento acústico e alguns retoques na pintura. Chamam atenção os painéis com o logo da escola seguido do epíteto "A Soberana", adotado por seus componentes devido ao fato de ser a escola com mais campeonatos no carnaval de Manaus.

Quando terminaram os discursos e após o rufar da bateria o intérprete da verde e rosa assumiu o microfone, o assessor parlamentar Prince do Boi, como é conhecido tanto na Vitória Régia quanto no Boi Caprichoso, ${ }^{6}$ em que foi amo do boi. Por atuar também na esfera política, fez um longo discurso para apresentar a escola e seu casal. De início em tom ameno, apenas exaltando seus companheiros de escola; mais à frente veremos que ele se exaltou mais um pouco (Figura 2). 
Prince cantou outros sambas antigos da verde e rosa, mas sua empolgação e a de torcedores da Vitória Régia, espalhados pela quadra iam de encontro à insatisfação de alguns torcedores da Aparecida. Uma conhecida minha e torcedora da Aparecida estava revoltada em sua mesa, falava e gesticulava, como quem faz pouco da apresentação da Vitória Régia. Chegava até mesmo a virar de costas para o palco. Já outro componente da Aparecida reclamava que o "convite era apenas para a diretoria e um monte de gente da escola foi" e que "a decoração da quadra tinha rosa demais" pro gosto dele. No lado da Vitória Régia, do palco da bateria pude observar ritmistas que estavam ao lado de onde Prince se apresentava, gesticulando e provocando os mestres de bateria da Aparecida, Paulinho e Lucas, que se exaltaram, pegaram a bandeira verde e rosa que estava na mesa, mas foram controlados por outros membros da escola. Logo a seguir de um dos sambas antigos da escola eles emendaram num coro provocativo de "Ih! F...! A 14 apareceu", numa referência ao bairro da Vitória Régia, a Praça 14. Ao receber as provocações Lucas e Paulinho começaram a encarar os jovens da bateria da Vitória Régia. Um dos diretores da Vitória Régia tentava desesperadamente controlálos. Junto de Lucas e Paulinho um ritmista da Aparecida, mais parrudo e de cara amarrada ajudava a criar mais tensão. Do outro lado, o diretor de bateria da verde e rosa chamava atenção dos demais, em seguida fazia sinais pedindo desculpas em direção ao palco. Próximo dali o casal da Vitória Régia que havia descido do palco em que se apresentava via-se enredado pelo furto do pavilhão por uma exaltada torcedora da escola que balançava a bandeira de forma ostensiva, talvez querendo atingir com as sacudidelas torcedores da Aparecida que estavam atrás do cercado das mesas. Ela foi contida pela própria porta-bandeira e alguns outros torcedores da escola da Praça 14 queocupavam a mesa em frente e que lhe tomaram a bandeira, devolvendo-a a quem pertencia de fato.

Já com o casal no palco de intérpretes e quando tudo parecia mais controlado, Prince do Boi convoca seus compatriotas para a guerra novamente fazendo questão de frisar, repetidas vezes, o verso "Vitória Régia, a campeã voltou" do samba de 2014. O que afastou a possibilidade de uma nova tensão foi o clima de fim de festa que começava a tomar conta da quadra, bem como a indiferença dos anfitriões. Ainda houve tempo para uma nova provocação - dessa vez por parte do apresentador da Aparecida, que bradava: "Acho que o pessoal da 14 bebeu demais, estão dizendo que a campeã voltou" - encarada, entretanto, como brincadeira. 


\section{REFLEXÃO E QUESTÕES FINAIS}

Daqui podemos prosseguir indicando algumas questões frutíferas para nossa reflexão sobre o ensaio de escola de samba. Um outro olhar pode ser lançado à análise do material sobre o ensaio e expandido ao desfile de uma escola de samba como aqui tomado. Essa caminha por perspectiva completamente diferente da carreira de Victor Turner, cuja trajetória intelectual avançara até o ponto de lançar o olhar sobre a experiência. Ele trouxe a temática do conflito e do drama social para a análise das relações e a montagem de uma cosmologia que, partindo desse ponto, chegasse a seu funcionamento sem perder a vitalidade intrínseca aos símbolos. Nesse momento o símbolo é o mediador da apreensão e da vivência da experiência (CAVALCANTI, 2012).

No processo de apreensão de sua antropologia da experiência, um importante interlocutor foi o dramaturgo Richard Schechner (2011) que, compreendendo o esforço de aproximação com o universo dramatúrgico empreendido por Turner já na elaboração da teoria do drama social, acompanha seu movimento no sentido da criação de uma teoria da performance. Como comprovamos em seu ensaio Pontos de contato entre o pensamento antropológico e teatral, traduzido para português e recentemente publicado em Cadernos de Campo, da USP. Segundo John Dawsey (2011), para a antropologia dentro desse campo a parceria entre Schechner e Turner como representantes de sua vertente dramatúrgica é de importância destacada.

Ambos os autores acabam por retroalimentar as teorias. Assim, tomando as ideias de Schechner sobre "comportamento restaurado", a teoria de análise simbólica de Turner (1985, p. XI) a partir da experiência ganha vida, segundo o próprio autor: “Aprendi com ele que toda performance é comportamento estruturado, que o fogo do significado irrompe da friç̧ão entre das madeiras duras e suaves do passado (...) e presente da experiência social e individual."

Buscando "lançar luz sobre a análise social", a teoria da performance serve a análise simbólica. São as duas combinadas que muita contribuição têm a dar, proporcionando assim inovadora reflexão sobre processos sociais performatizados, ainda que dirimidas algumas questões intrínsecas a essa teoria. Foi o próprio Schechner quem propôs considerar "qualquer ação humana, ou produto dessa ação, a partir do enquadramento, ou frame, da performance". As performances, bem como os símbolos, são coisas boas para pensar e "fazer pensar". Destacando-se os momentos mais eletrizantes de uma performance é possível trazer à tona o "não eu" e o "não não eu" de quem a vivencia (DAWSEY, 2011). 
Ao estabelecer os pontos de contato, conforme citado, Schechner chama atenção para o momento em que os performers e até mesmo o público são alterados pela atividade de "performatizar". O aspecto posicional é notável no sentido de colocar não apenas o espectador e o performer, mas encarar este último mais como agente do que como profissional da performance num exercício de relativização. Assim o complexo modelo do liminoide construído por Turner (1982) em From ritual to theatre emerge com toda a sua potencialidade, e tudo isso vai além de muito do que propõe o próprio modelo de Turner e Schechner. Vai além de investigar a intensidade da performance ou a inquietude do "performado". O papel da audiência, como muito bem frisou Schechner (2011, p. 223), é de fundamental importância:

Mudanças na audiência levam a mudanças na performance. Michele Anderson descreve três formas de vodu que ela pesquisou recentemente no Haiti: uma forma ritual/social apenas para os haitianos (embora ela estivesse lá); uma forma teatral para haitianos e turistas; e uma forma teatral/comercial apenas para turistas.

Para Schechner (2011, p. 225), as performances têm sete fases: treinamento, oficinas, ensaios, aquecimentos ou preparações imediatamente antes da performance, a performance propriamente dita, esfriamento e balanço. Ele, aliás, critica a "pouca atenção dada a pesquisadores em fases diferentes da performance propriamente dita". Façamos então o exercício por ele proposto ao deslocar o olhar da performance no caso das escolas de samba.

Vemos no ensaio da Aparecida, por exemplo, a marca da rivalidade. A troca agonística em que receber uma coirmã é simultaneamente com ela rivalizar. Uma competição em que é preciso não só receber melhor, como ser o melhor visitante, o que doa mais, sendo dádiva, no nosso caso, o samba. Uma arena em que a rivalidade se encena e com ela os pertencimentos individuais, expressos em cores e comportamentos.

Os ensaios nas escolas acontecem antes mesmo da definição de um samba a ser cantado na performance que é a sua essência, o desfile. A definição de qual será a música cantada nos desfiles faz parte do processo de sua assimilação pelo conjunto de desfilantes. Uma série de eventos acontece no dia que congrega maior público na quadra de uma escola de samba, o chamado ensaio comercial ou ensaios-bailes. Já em Carnaval carioca: dos bastidores ao desfile, vemos emergir tal conceito na etnografia de Maria Laura Cavalcanti (2006, p. 133) sobre o carnaval da Mocidade Independente de Padre Miguel:

Esses ensaios-bailes são também uma competição, perpassada por tensões. Uma delas deriva do caráter comercial dos ensaios, opon- 
do os "de fora" (termo que, neste contexto de uso, designa aqueles que vêm para um baile) aos "de dentro" (termo que designa aqui as pessoas diretamente envolvidas na produção de um desfile, e também os moradores dos arredores da quadra). Na medida em que a quadra vai enchendo, "o pessoal daqui do lugar fica lá fora olhando. Quer achá-los, vai lá fora", me dizia seu Quirino tocador de cuíca e antigo integrante da bateria.

A partir da perspectiva da ala de passistas da Estação Primeira de Mangueira, em Samba no pé e na vida: carnaval e ginga de passistas de escolas de samba, Simone Toji (2006) registra três categorias de performances das escolas de samba, preparatórias da principal, que é o desfile, e assim demarcadas no esquema de Schechner como "ensaio", são elas: "ensaios de bateria", "apresentações do grupo show" e "ensaios de rua". Em cada um deles encontramos aproximações das categorias aqui apresentadas. A primeira se conecta com a posição entre os "de dentro" e os "de fora". Nos "ensaios de bateria", também chamados de ensaios comerciais, elementos da performance das passistas ligam sua apresentação à participação de um público "de fora". Elas geralmente usam as roupas de desfile na apresentação do "grupo show". Seus meneios e trejeitos são voltados para esse público, que não é assíduo na quadra. O aspecto posicional também se vincula a esse tipo de performance. A apresentação da ala de passistas, bem como outros segmentos da escola (bateria, baianas, velha guarda...) não segue um modelo processional como o do desfile (TOJ, 2006).

Os ensaios de rua, como vimos no exemplo da Aparecida, são ricos para elucidar também as redes de relações sociais da escola de samba com seu bairro, com sua cidade. A categoria que seu Quirino apresenta na pesquisa de Maria Laura Cavalcanti, aqui citada, opõe duas classificações fundantes de outra categoria utilizada na antropologia urbana. São os "de dentro" e os "de fora" que determinam um espaço moral na cidade chamado de pedaço (MAGNANI, 2002, 2003).

Como mencionamos, esse pertencimento é, aliás, negociado nos ensaios em que o frequentador assíduo torna-se do pedaço, e é possível tornar-se do pedaço mediante a apresentação de um pertencente ao pedaço. Pertencimento torna-se objeto de troca; "a performance adquire, assim, novos significados e favorece novas relações" (AGIER, 2011, p. 177).

Há outro aspecto não apresentado neste trabalho, mas que vale a pena ser aprofundado em estudo exclusivamente a ele dedicado. Os ensaios técnicos na pista de desfile das escolas de samba tornaram-se parte do ciclo que envolve escolas de samba Brasil afora. No Livro de ouro do carnaval brasileiro temos uma sintética descrição desses eventos por Felipe Ferreira (2004, p. 370-371): 
a partir da década de 1990, com o surgimento dos primeiros ensaios técnicos realizados na pista do próprio sambódromo, o evento foi aos poucos assumindo um caráter de um verdadeiro desfile antecipado, atraindo cada vez mais pessoas interessadas em assistir à passagem das escolas sem fantasias ou alegorias, mas com seus componentes dançando ao som de bateria e puxador, numa preparação para a apresentação oficial. (...) esses ensaios técnicos vêm tendo um público cada vez maior com o passar dos anos, buscando, ao que parece, um momento de contato simples e direto com o ritmo e a música, sem a mediação das fantasias e grandes alegorias, reservadas para o momento da disputa nos dias do desfile oficial. (...)A partir dos preparativos para o Carnaval de 2001, miIhares de espectadores passaram a ocupar a área de desfile, fazendo com que, já nos ensaios para o Carnaval 2004, as arquibancadas passassem a ser abertas para poder acomodar o público que outrora se comprimia nas laterais de pista.

Pude acompanhar alguns desses ensaios no sambódromo carioca durante a pesquisa de mestrado em que atestamos sua importância não apenas na vida cultural da cidade, como no contexto das escolas de samba, além do óbvio estágio de preparação para os desfiles (BARBIERI, 2012). Era ali que os dirigentes das pequenas escolas, que nem mesmo desfilavam no sambódromo, encontravam os dirigentes das grandes escolas do Grupo Especial. Ali negociavam desde fantasias a reaproveitar até componentes para completar o contingente. Um dos entrevistados me contou até sobre um presidente que negociou ali, na beira da pista, a compra de adereços a reutilizar em sua escola, fora da cidade do Rio de Janeiro.

Há ainda os casos pré-ensaio e pós-ensaio. Sim, pois ali, do lado de fora da quadra, uma extensão daquela performance do interior da quadra é encenada. A briga do lado de fora corre de boca em boca até o interior da quadra. As fofocas circulam e são levadas para o interior do ensaio. As negociações acontecem. Os moradores do entorno aproveitam para vender quitutes ou bebidas entrando na rede envolvida na performance. Ou podem mobilizar-se para impedir a realização daquele evento, que atrapalha o trânsito e suja as calçadas com barraquinhas e ambulantes que vendem bebidas. Uma investigação das barraquinhas merece também atenção especial nos estudos de carnaval e escolas de samba.

Enfim, a importância das escolas de samba nos estudos da cidade parece mais que confirmada na antropologia. Adentrar esse universo e esgotar a exploração do ciclo ritual - em que os ensaios estão imersos - que envolve as escolas de samba para além do Rio de Janeiro é fator de fundamental importância. 


\section{NOTAS}

1 É a escola que tem atualmente o maior número de títulos no carnaval de Manaus seguida pela extinta Escola Mixta da Praça 14 de Janeiro e por sua arquirival Vitória Régia com dez títulos.

2 A Aparecida foi a sétima escola do Grupo Especial, da primeira divisão das escolas de samba de Manaus, a desfilar na noite de sábado, 18 de fevereiro.

3 Rainha, madrinha e musa da bateria.

4 Em Barbieri (2009) já demonstrei a preocupação dos carnavalescos com a abertura das passarelas na Cidade do Samba durante a construção das alegorias para o carnaval carioca.

5 Já contando com o título de 2014, quando todas as escolas foram declaradas campeãs.

6 Muitos integrantes dos bois de Parintins ocupam cargos importantes também no carnaval de Manaus. Fato merecedor de atenção em futuras pesquisas e que possivelmente demonstra as interlocuções entre elementos das duas festas, entre eles a rivalidade entre agremiações.

\section{REFERÊNCIAS BIBLIOGRÁFICAS}

AGIER. Michel. Situações e comunidades: a cidade em movimento. São Paulo: Ed. Terceiro Nome. 2011.

BARBIERI, Ricardo José. Cidade do Samba: do barracão de escola às fábricas de carnaval. In: CAVALCANTI, Maria Laura; GONÇALVES, Renata. Carnaval em múltiplos planos. Rio de Janeiro: Aeroplano. 2009. 2012.

. A Acadêmicos do Dendê quer brilhar na Sapucaí. Jundiaí: Paco Ed.

CAVALCANTI, Maria. Laura. Carnaval carioca: dos bastidores ao desfile. Rio de Janeiro: UFRJ. 2006.

. Luzes e sombras no dia social: o símbolo ritual em Victor Turner. Horizontes Antropológicos, Porto Alegre, ano 18, n. 37, p.103-131, jan.-jun. 2012.

DAWSEY, John. Schechner, teatro e antropologia. Cadernos de Campo, São Paulo, n. 20, p. 207-211, jan-dez. 2011.

FERREIRA, Felipe. O livro de ouro do carnaval brasileiro. Rio de Janeiro: Ediouro. 2004.

MAGNANI, José. Guilherme. De perto e de dentro: notas para uma etnografia urbana. Revista Brasileira de ciências sociais, v. 17, n. 49, 2002, p, 11-29.

. Festa no pedaço. São Paulo: Unesp. 2003.

SALES, Daniel. É tempo de sambar: história do carnaval de Manaus (com ênfase às escola de samba). Manaus: Editora Nortemania. 2008. 
SCHECHNER, Richard. Pontos de contato entre o pensamento antropológico e teatral. Cadernos de Campo. São Paulo, n. 20, p. 213-236, jan-dez. 2011.

TOJI, Simone. Samba no pé e na vida: carnaval na ginga das passistas de Escola de Samba Estação Primeira de Mangueira. Dissertação (Mestrado). Programa de Pós-graduação em Sociologia e Antropologia, Universidade Federal do Rio de Janeiro, Rio de Janeiro. 2006.

TURNER, Victor. O processo ritual. Petrópolis: Vozes. 1974.

. From ritual to theatre: the human seriousness of play. New York: PAJ Publications, 1982.

. Foreword. In: SCHECHNER, Richard. Between theater and anthropology. Philadelphia: University of Philadelphia Press, 1985, p. xi-xii.

. Schism and continuity in na african society. Manchester: Manchester University Press, 1996.

Ricardo José de Oliveira Barbieri é doutorando em antropologia pelo PPGSA/

UFRJ e autor do livro A Acadêmicos do Dendê quer brilhar na Sapucaí (2012).

Recebido em: 11/11/2014

Aceito em: 25/03/2-15 